\title{
E agora, doutor, no que você pode contribuir?
}

\author{
And now, doctor, on what you can contribute?
}

\author{
Priscila Maria Vasconcelos Porto ${ }^{1}$ \\ Vitor Coutinho Vieira dos Santos ${ }^{2}$ \\ Anete Alberton ${ }^{3}$ \\ Carlos Ricardo Rossetto ${ }^{4}$
}

Este caso descreve como algumas variáveis influenciaram o desenvolvimento de uma inovação direcionada a melhorar os processos de produção animal e de conservação de uma espécie de ovino no município de Morada Nova/CE. As atividades de um pesquisador da Empresa Brasileira de Pesquisa Agropecuária - Embrapa, puderam ser entendidas como Capacidade Absortiva -ACAP, e foram determinantes durante o processo de pesquisa e desenvolvimento da inovação.

O objetivo deste estudo é compreender a influência da ACAP na inovação, desde seu desenvolvimento até a implantação. O desenvolvimento de tecnologias e inovações são os principais resultados que a Embrapa entregou para a sociedade desde sua fundação.Atualmente, o foco da empresa é aumentar sua geração de inovação mediante ações estratégicas, gerenciais, metodológicas e outras. Assim, este estudo aponta na direção de identificar melhor quais variáveis podem influenciar na geração de inovação.

$\mathrm{Na}$ experiência aqui relatada, instituições de desenvolvimento regional perceberam a necessidade de uma solução de cunho científico, e assim surgiu a oportunidade de desenvolver um projeto de quatro anos de melhoramento genético animal para resgate da raça, aumento de produção e adaptação às condições climáticas e alimentares predominantes na região. Os dados foram provenientes da análise de documentos elaborados pelos pesquisadores da Embrapa ligados a áreas socioeconômica e de melhoramento genético animal. O dilema central reside em como o pesquisador estabeleceu a interação com os produtores de ovinos, como o Zé e, por meio dela, pôde desenvolver uma inovação que transformasse a realidade da ovinocultura da região de Morada Nova/CE.

\section{Introdução}

Era uma manhã ensolarada na cidade de Morada Nova, no estado Ceará, e Zé olhava para o céu;via nuvem, mas não via água. Ele, como milhares de produtores do semi-árido brasileiro, travava anualmente um cabo de guerra entre a seca e a vontade de continuar vivendo de sua propriedade. Mas quem pode ajudar o Zé com sua produção de ovelhas? Como acabar com o sofrimento que traz a morte dos animais?

Em 2010, devido a novas tecnologias de produção e assistência técnica, política e social, seu Zé tinha muita gente em volta, mas mesmo com tantas pessoas perguntando ou falando o quefazer para produzir e o que fazer com os animais, as coisas não mudavam no ciclo desgostoso de vida e morte de seus bichos.

Analisando o contexto, a necessidade de absorver conhecimento e a geração de inovação proporcionada pelos estudos dos pesquisadores, Zé pensou: - E agora, Doutor, no que você pode contribuir?

Mestranda em Administração pela Universidade do Vale do Itajaí (UNIVALI -SC). Brasil. Afiliação: Universidade do Vale do Itajaí - UNIVALI. Lattes: http://lattes.cnpq.br/2667762910740812Email: priscilaportopesquisa@yahoo.com

2 Mestre em Administração pela Universidade do Vale do Itajaí (UNIVALI -SC). Brasil. Afiliação: Universidade do Vale do Itajaí - UNIVALI. Lattes:http://lattes.cnpq.br/5064793651959072Email: vitordossantos@gmail.com

3 Doutorado em Engenharia de Produção pela Universidade Federal de Santa Catarina (UFSC). Brasil. Afiliação: Universidade do Vale do ItajaíUnivali. Lattes: http://lattes.cnpq.br/5451127583047484Email: anete@univali.br

4 Doutorado em Engenharia de Produção pela Universidade Federal de Santa Catarina, UFSC. Brasil. Afiliação: Universidade do Vale do Itajaí UNIVALI. Lattes: http://lattes.cnpq.br/2353731975740976Email: rossetto@univali.br 


\section{Origem da Raça Morada Nova}

A raça Morada Nova foi descrita em 1937. Uma raça de ovinos deslavada e adaptada para o sertão nordestino (DOMINGUESapudFACÓet al., 2008). Apesar dos desafios de produção animal que o semiárido nordestino apresenta, a raça é caracterizada como boa fornecedora de carne e pele, o que traz retorno positivo na venda de animais e produtos associados(SILVA et al., 2015).

\section{O Caso}

Zé conhece um "dotô", maneira como se referia ao pesquisador da Embrapa, Alexandre. No apêndice A pode-se encontrar o significado de muitas expressões regionais relatadas no caso. O pesquisador da Embrapa, Facó, veio falar com Zé sobre algumas ovelhas que o cearense e outros produtores da cidade de Morada Nova criavam.Masera ele mais um perguntando: Quando? Quanto?Quem?Como? -além de outras coisas mais, sem devolver sequer um muito obrigado?Seu Zé, pensando nisso, lembrou-se de um poema de Patativa do Assaré, que dizia:

Você teve inducação, Aprendeu muntaciença, Mas das coisa do sertão Não tem boa esperiença. Nunca fez uma paioça, Nunca trabaiou na roça, Não pode conhecê bem,

Pois nesta penosa vida, Só quem provou da comida

Sabe o gosto que ela tem

Você é muito ditoso, Sabe lê, sabe escrevê, Pois vá cantando o seu gozo, Que eu canto meu padecê. Inquanto a felicidade Você canta na cidade, Cá no sertão eu infrento A fome, a dô e a misera.

Pra sê poeta divera, Precisa tê sofrimento.

(Patativa do Assaré, Cante Lá que eu Canto Cá, 1978).

Mais uma vez, uma instituição (pública, privada, ONG etc.) foi falar com o Zé e seus companheiros produtores. A dúvida que pairava era:"será que, mais uma vez, esse povo vem e vai e nada muda"?

Desta vez, era o Serviço Brasileiro de Apoio às Micro e Pequenas Empresas - Sebrae que queria desenvolver a cadeia de produção de ovinos da raça Morada Nova por meio do projeto Aprisco (Apoio a Programas Regionais Integrados e Sustentáveis da Cadeia da Ovino caprino cultura). Já no início, o Sebrae encontra um obstáculo comum a quem quer desenvolver sócio e economicamente de forma sustentável 
uma região - Com quem falar? Quem manda, coordena, influencia e apóia as pessoas? Muitas vezes, o referencial de autoridade social, política ou institucional, não é a mesma pessoa ou instituição que, na prática, possui a liderança que os indivíduos identificam como real.

Mas o Zé sabe de tudo isso, sabe da qualidade e da resistência, não precisa ler uma linha para saber que a raça Morada Nova, traz o pão, o leite eo dinheiro para a casa. Ele diz que promessa de chuva é a mesma coisa de promessa de político, existe, mas é difícil de ver. Então, quando "as autoridade" chegam , ora o prefeito, ora o governo do estado, muitas vezes vêm para falar e,em poucas vezes, para ouvir.

Porém, o Sebrae queria falar com os produtores, não com um ou outro, queria falar com todos, e foi procurar a associação. Para chegar nela, indicaram o produtor Zé para ajudar a encontrar o pessoal, e perguntaram para o Zé:

Consultor: Zé, o senhor sabe como está a associação?

Zé: Estar aí!

Consultor: Quando acontecem as reuniões?

Zé: Reunião?

Consultor: Isso! Quando os produtores vão para a sede da associação?

Zé: Sede? Ó,deve fazer uns dez anos que a gente não se encontra!Os produtor se fala pra se ajudar nos problema que aparece, mas do jeito que eu acho senhor precisa não acontece faz um bocado.

O Sebrae levantou inúmeras informações sobre a região, a produção de ovinos, dados demográficos e outros para embasar sua atuação e atender aos objetivos que possui no projeto institucional. Uma das estratégias para isso foi contatar a Embrapa para firmar uma parceria técnica. O levantamento mostrou que a produção e a geração de renda na região estavam em declínio e uma das possíveis intervenções era a melhoria do sistema de produção.

Seu Zé estava percebendo que os animais estavam diferentes, a cada geração de cordeiros os animais não eram iguais. Olhando para o campo marrom, com os animais descansando debaixo do pé Jurema, ele se lembrava que:

"Era mais carnuda, mais parruda. Os corderim brilhavam no sol, num adoentava tão fácil... nas budegas, nos mercantil, a gente conseguia um preço arretado. Mas também, quando a chuva não vem, os animais morrendo, a gente faz de tudo pra não perder os bichos, aí nas monta eles

se misturam tudim. A gente conversava que a mistura tava acabando com os Morada Nova. A gente falava, mas não dizia. Ninguém queria ver o que estava vendo,até falei com o meu minino, os animais tão cada dia diferente, vamos perde os Morada Nova!"

Após a parceria fechada, os produtores da associação foram convidados para uma reunião na prefeitura, para ver o que poderia ser feito. Foram mais de cinquenta.

Inicialmente, um pesquisador de melhoramento genético animal, da Embrapa Caprinos e Ovinos, apresentou uma palestra que abordava diversos aspectos da produção de ovinos. Logo no início, um produtor pediu a palavra e lançou a pergunta: "E aí dotô, no que você pode contribuir?" Isso refletia duas necessidades, a melhoria imediata dos rebanhos e uma abordagem diferente de interação técnica e social com aquele público.

Um dos aspectos da palestra foi falar sobre escrituração zootécnica, um conjunto de práticas relacionadas às anotações da propriedade rural, que possui atividade de produção, e também às anotações do controle do rebanho, com fichas individuais por animal, registrando sua genealogia, ocorrências e desempenho. Nessas anotações são registrados o momento (datas), a condição e a extensão de importantes ocorrências, como nascimento, coberturas, partos, enfermidades, morte, descarte, etc.

O pesquisador explicou sobre Teste de Desempenho, que tem como objetivo: identificar diferenças genéticas entre animais candidatos a reprodutor, otimizar a negociação de animais testados,melhorar 
os indicadores produtivos, conscientizar os produtores da importância de um programa de avaliação de desempenho de reprodutores em confinamento, ou em campo, e outros.

Um dia, o Zé comprava insumos no centro da cidade quando encontrou um amigo que foi na palestra, mas não quis fazer parte do projeto,e começou uma conversa bem desconfiada:

Amigo: Zé, como estão as coisas? E osôme, já passou pra eles tudo, já respondeu aquelas perguntas e aquela ruma de coisa?

Zé: Eles estão juntos todo tempo, nos vem dizem um mundaréu de coisa e vão embora. Eles fazem um negócio chamado Dia de Campo. Mostraram sobre pesar o animal, como pegar o animal, umas técnicas modernas, falaram sobre os aprisco, a cura do umbigo que sempre dá aqueles problema. Tu acredita que o dotô pesou todos os animais? Falamos sobre as matrizes, as marrãs. Falava de organizar a cobertura, estação de monta. A necessidade de se fazer a estação de monta.

Amigo: Como é macho? Estação do quê? É coisa pra trem é?

Zé: Que isso? Tu ta frescando é? É para organizar os animais, separar por idade e fazer uma cobertura certinho separando a criação. A gente reunia os animais e ele dizia se estava correto. Foi jogo aberto, aberto mesmo, não tinha blábláblá.Agente falava que as coisas não funcionavam, de um jeito ou de outro, ele ouvia tudo.Agente ia resolvendo as coisa, todo mundo tinha vez.

Amigo: Foi mesmo? Tá diferente, ein?!

Zé: Rapaz, tu tá é por fora!Quando ele não entendia o que a gente falava, ele pedia pra gente contar um exemplo de alguma propriedade, ou uma coisa que tá acontecendo com todo mundo. Ele não ficava no pedestal não, a gente até esquecia que ele era dotô.

Esse aspecto, de como foi estabelecida a comunicação e a interação,foi muito positivo. A forma como as questões técnicas foram abordadas, as capacitações e, principalmente, a estratégia de compartilhar, levantar e registrar os conhecimentos locais e técnicos estabeleceu o ambiente de confiança e a construção de um modelo de produção altamente adequado às necessidades dos produtores da região. Era comum a utilização de metáforas, situações do cotidiano, casos e exemplos das rotinas na propriedade serem usados para aumentar a troca de informações e o alinhamento de orientações e diálogos. Mas nem tudo eram flores.Um dia, o Zé conversando com o filho contou uma "raiva" que ele passou com o pesquisador.

Filho: Pai, que aperreio é esse? Te acalma.

Zé: Arriégua, não tem condição, não. Sabe aquele comprador de animal da capital que revende as carcaças pra restaurante? Pois então, ele tava doido, com gosto de gás, muito empolgado, pra comprar tudim. Ficou foi besta de ver a qualidade do bicho. Tudo igualzim, gordos, até me perguntou se eu tava dando aqueles remédios que fazem os bichos crescerem. E tem mais, me fez uma oferta excelente.

Filho: Tu vendeu tudo, foi?

Zé: la vender, mas o dotôzim veio que nem uma bala, dizendo alto que num sei o quê, que eu tinha que pensar no projeto, que só tinha se passado um ano pranum sei o quê, que ainda tinha que ter mais uns anos, blábláblá.

Filho: E aí?

Zé: Tapaz, o ôme tava tão alterado que eu fiquei até com medo e num vendi, acredita? Tive que dar um voto de confiança pro ôme. Até agora ele foi correto com a gente e tudo o que nós estamos fazendo

tá dando certo, tudo sempre preto no branco, então ele sabe o que tá falando.

Filho: Tô entendendo, pai, e isso vai até quando?

Zé: Sei não, ele fala em três anos, mas vou the dizer um negócio. Nunca vi os bichos assim:a cada ruma de cordeirinho que nasce, vem os bichim mais bonitinho, mais fortes, tudo igualzinho, resistente, ficam tudo parrudo. Rapaz, se for desse jeito, daqui a pouco a gente vai ver de novo aqueles Morada Nova, como no tempo que a gente era criança. Ôxi, era os bichos mais bonitos que existia. Isso vai acontecer filho, eu tô acreditando. 


\section{APÊNDICES}

Quadro 1 - Palavras usadas no texto comum na linguagem do sertanejo do interior do Ceará.

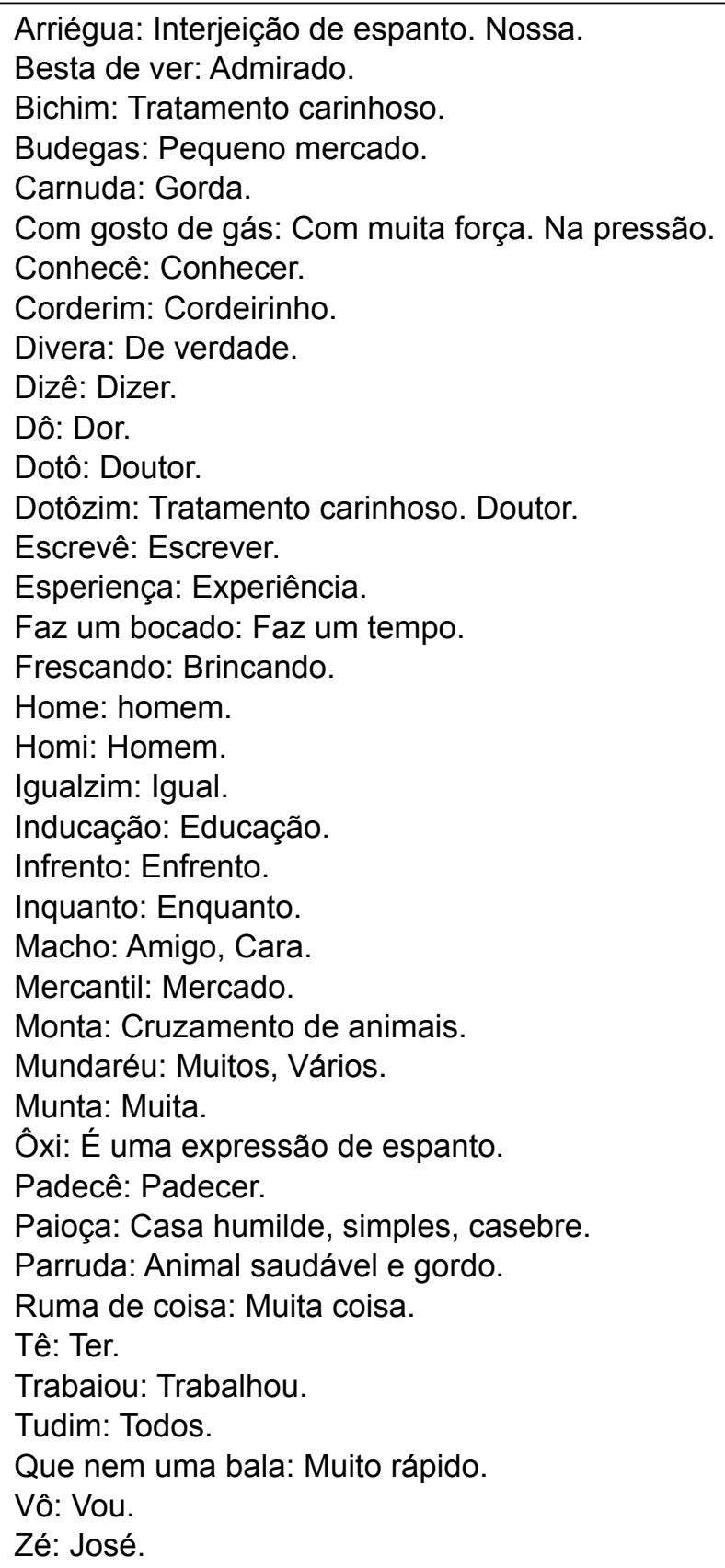

\section{Referências}

FACÓ, O.; PAIVA, S. R.; ALVES, L. R. N.; LOBO, R. N. B.; VILLELA, L. C. V. Raça Morada Nova: Origem, Características e Perspectivas. Sobral, CE: EMBRAPA-CNPC, 2008. 43p. (EMBRAPA-CNPC. Documentos, 70).

MAGALHÃES, K. A. et al. Panorama e perspectiva mundial da ovinocultura e caprinocultura., 2016 Disponível em: <https://www.embrapa.br/busca-de-noticias/-/noticia/8698648/estudo-aponta-tendenciaspara-caprinocultura-e-ovinocultura-nos-cenarios-nacional-e-internacional >. Acesso em: 30 abr. 2016

SILVA, M. S. DA et al. Principal component analysis for evaluating a ranking method used in the performance testing in sheep of Morada Nova breed. Semina: Ciências Agrárias, v. 36, n. 6, p. 3909, 9 dez. 2015. 


\title{
NOTAS DE ENSINO
}

\section{Resumo do caso de ensino:}

Este caso descreve como algumas variáveis influenciaram o desenvolvimento de uma inovação direcionada a melhorar os processos de produção animal e de conservação de uma espécie de ovino no município de Morada Nova/CE. O caso conta as atividades de um pesquisador da Empresa Brasileira de Pesquisa Agropecuária - Embrapa, entendidas como Capacidade Absortiva - ACAP, que foram determinantes durante o processo de pesquisa e desenvolvimento da inovação da espécie, principal fonte de renda da região. Os fatos ocorreram em 2010, e o dilema central reside em como o pesquisador estabeleceu a interação com os produtores de ovinos, como no caso do Zé e, por meio dela, pôde desenvolver uma inovação que transformasse a realidade da ovinocultura da região.

Palavras-Chave: Capacidade Absortiva, Inovação, Embrapa.

\begin{abstract}
This case describes how some variables influenced the development of an innovation aimed at improving the processes of animal production and conservation of species of sheep in the municipality of Morada Nova/CE. The case describes the activities of a researcher from Embrapa - Brazilian Agricultural Research Corporation, understood as the Absorptive Capacity - ACAP, who were instrumental during the process of research and development of innovation of the species, the main source of income for the region. We are in 2010 and the central dilemma lies in how the researcher established the interaction with the producers of sheep, as in this case Zé, and, through it, was able to develop an innovation that transform the reality of sheep production in the region of Morada Nova/CE.
\end{abstract}

Keywords: Absorptive Capacity, Innovation, Embrapa.

Objetivo de ensino:Proporcionar aos estudantes maior familiaridade com o conceito de capacidade absortiva, bem como suas dimensões (absorção, aquisição, transformação e aplicação do conhecimento explorado) e sua influência no ambiente, considerando os diferentes atores e as múltiplas variáveis intervenientes nos processos de análise e interpretação do conhecimento desenvolvido em uma atividade econômica.

\section{Relações com os objetivos de um curso ou disciplina}

Deste modo, considerando o objetivo deste estudo (colocado acima), alguns objetivos específicos foram traçados visando ajudar os estudantes a terem maior entendimento sobre o caso estudado e a disciplina Estratégia das Organizações:

1. Identificar como o desenvolvimento de inovações pode ser influenciado pela capacidade absortiva. Atividades que foram realizadas para entender o cenário em que o desenvolvimento da produção acontece. Algumas dessas atividades podem ser classificadas como condições ambientais que incentivam a capacidade Absortiva (CASSOL, 2017; COHEN \& LEVINTHAL, 1989, 1990; e LANE, KOKA, \& PATHAK, 2006).

2. Analisar como as dimensões da ACAP influenciam no cenário ao qual se pretende impactar. Integração dessas informações ao projeto de pesquisa e, levando em consideração aquilo que surge como demanda, até os aspectos do contexto dos produtores que se pretende impactar e aquilo que será desenvolvido dependem de algumas atividades de processamento das informações que, para o estudo da capacidade absortiva,são: aquisição, assimilação, transformação e aplicação (Exploitation). (CHAUVET, 2014; DURISIN, 2007; FLATTEN et al., 2011; TODOROVA;).

3. Analisar como as atividades de pesquisa e desenvolvimento que são caracterizadas como atividades de capacidade absortiva geram inovação nesse caso (COHEN \& LEVINTHAL, 1989, 1990). Inovação e 
geração de impacto de tecnologias agropecuárias: neste ponto, procura-se identificar como a inovação no meio rural possui particularidades e diferenças de outras práticas de pesquisa(EMBRAPA, 2014; LIMA et al., 2004; PAEZ, 2000).

\section{Fonte e Métodos de Coletas}

Os dados para elaboração do caso foram obtidos por meio de documentos elaborados pelos pesquisadores da Embrapa ligados às áreas de socioeconômica e melhoramento genético animal (BELCHIOR, 2016; FACÓ et al., 2008), que registra e sistematiza de forma detalhada as experiências passadas em todas as fases da pesquisa.

A inovação baseou-se em dados técnicos, científicos(SILVA et al., 2015), estatísticos e socioeconômicos, ligados ao melhoramento genético animal e à economia (Anexo A). Porém, evidenciamos nesse caso uma série de atividades que delinearam a definição, desenvolvimento e os resultados da inovação que foram focadas na integração e relação do pesquisador com o público (produtores). E, por fim, a partir de informações levantadas e processadas na experiência e os desafios dos produtores naquele local específico.

Disciplina sugerida para o uso do caso: Estratégia das Organizações

\section{Possíveis tarefas para propor aos alunos}

O debate em plenária ocorrerá a partir da situação-problema: Será que, com as atividades de levantamento das informações, as atividades de processamento e as atividades que utilizaram essas informações para o desenvolvimento da pesquisa, o pesquisador trouxe alguma contribuição que transformasse a realidade da produção pecuária do Zé?

Ao introduzir o caso para ensino, o debate promoverá entre os estudantes sentimentos de assimilação ou aproximação com diferentes formas de agir de cada um dos personagens que atuam no caso apresentado. Então, podem-se fazer os seguintes questionamentos:

1. Qual é a relação entre capacidade de absorver informações do ambiente e geração de inovação?

2. Quais atividades do pesquisador podem ser classificadas como capacidade absortiva?

3. Em quais momentos aquilo que era realidade da vida do Zé influenciou o processo de desenvolvimento completo da tecnologia?

4. Quais rotinas da organização podem ser classificadas como processos de capacidade absortiva?

5. Quais as atividades que podemos identificar como dimensões da ACAP: aquisição, assimilação, transformação e aplicação (exploitation)?

A partir das questões poderemos sugerir discussões sobre o caso e as fundamentações teóricas para dar suporte à reflexão.

Discussão da questão um: Essa questão busca a reflexão sobre a importância das bases de investigação para geração de inovação. Considerando o fato de que a inovação é algo que traz um nível de impacto sobre o ambiente, um grau de transformação na realidade em que será implementado, há uma relação entre inovação e o conhecimento das demandas e desafios do ambiente. $O$ docente deve diferenciar e ressaltar as opiniões e informações que partem dos estudantes quando falam do problema da produção animal no semiárido ou em situações complexas como essa no seguinte sentido: 1) há informações técnicocientíficas sobre os desafios enfrentados para a produção animal nestas regiões (Anexo $A$ ), o pesquisador já detinha as informações técnicas para desenvolver soluções, mas empenhou um grande esforço para levantar as informações fundamentais para o desenvolvimento da inovação e 2) Informações não técnicas, mas do contexto da vida do Zé e dos produtores de ovinos Morada Nova.

Enfim, é importante salientar que há uma diferença entre orientação no desenvolvimento de tecnologia com dados puramente técnicos, científicos e estatísticos, e uma orientação que adiciona esses dados para imersão na realidade local, onde se busca dados culturais, sociais, de manejo, de costumes, etc. 
Base teórica: serão usados dois conceitos para nos balizar sobre o que é inovação:

1. Inovação é a "implementação de um produto (bem ou serviço) novo ou significativamente melhorado, ou um processo, ou um novo método de marketing, ou um novo método organizacional nas práticas de negócios, na organização do local de trabalho ou nas relações externas" (OCDE, 1997).

2. Inovação é a "introdução de novidade ou aperfeiçoamento no ambiente produtivo e social que resulte em novos produtos, serviços ou processos ou que compreenda a agregação de novas funcionalidades ou características a produto, serviço ou processo já existente que possa resultar em melhorias e em efetivo ganho de qualidade ou desempenho" (BRASIL, 2016).

No contexto do caso, os produtores não buscavam tecnologias novas. Não Ihes interessava mais uma instituição ou consultores trazendo pacotes, ou kits, ou fórmulas, ou até novos animais não adaptados para serem introduzidos na região. Tudo isso é comum e são soluções e práticas validamente questionáveis, pois não solucionam ou são temporárias. O que eles desejavam era uma inovação, algo que trouxesse impacto, mudasse indicadores, redirecionasse números.Enfim, é importante discutir a diferença entre solução tecnológica e inovação.Além disso, sobre o que no caso os produtores desejavam.

Discussão da questão dois: Neste ponto, é possível fazer uma reflexão e debate sobre o conceito de capacidade absortiva - ACAP. Desde as teorias sobre capacidade dinâmicas - CD até a ACAP para entender o fenômeno de forma abrangente e aplicá-lo no caso. No relato das falas dos produtores há informações sobre como era a relação entre o pesquisador e público envolvido, sendo possível perceber tipos de informações que o pesquisador já possui de fontes técnicas, mas buscou nas propriedades particularidades que poderiam evidenciar e influenciar o nível de produção.

Com as informações sobre produção de ovinos no Brasil, perfil socioeconômico das propriedades que possuem ovinocultura e a utilização de melhoramento genético animal (Anexo A), podemos ver que o manejo de animais, influenciado pela necessidade de produção e a utilização de animais como fonte de troca e dinheiro, muitas vezes determinam o menor desempenho, pois animais melhores e mais adaptados podem ser vendidos em uma situação de dificuldade, ou cruzados com outras raças que, por exemplo, não são adaptadas.

Base teórica: De acordo com Meirelles e Camargo (2014), o fenômeno das capacidades dinâmicas (CD) nas organizações constitui um ramo de grande interesse para administração, em campos diversos do conhecimento. O tema é bastante discutido internacionalmente e tem feito parte de estudos ligados à inovação, vantagem competitiva, desenvolvimento organizacional, estratégia, entre outros temas. O teórico mais referendado sobre CD é David Teeceet al.(1997) e, para eles:

Capacidade dinâmica é definida como a habilidade da firma em integrar, construir e
reconfigurar competências externas e internas em ambientes de mudança rápida. As
competências são entendidas como o conjunto de rotinas e processos organizacionais
(específicos à firma), cujo desempenho é proporcionado pela posse de ativos específicos
(difíceis ou impossíveis de imitar). O termo "dinâmico" refere-se à capacidade de renovar
competências de modo a alcançar a congruência com o ambiente de negócios em
constante mudança; certas respostas inovadoras são necessárias quando o tempo de
colocação no mercado e tempo são críticos, a taxa de mudança tecnológica é rápida, e a
natureza da concorrência futura e comercial difícil de determinar. O termo "capacidades"
enfatiza o papel chave da administração estratégica em adaptar, integrar e reconfigurar
as competências organizacionais internas e externas, recursos e competências funcionais
para corresponder às exigências de um ambiente em mudança" (TEECE; PISANO;
SHUEN, 1997).

Os componentes da CD podem ser definidos como comportamentos, habilidades organizacionais. São os componentes da CD: um conjunto de características que podem estar envolvidas com aspectos-chave da organização, como liderança, inovação, flexibilidade operacional, empreendedorismo, etc. Dos textos mais antigos sobre o tema, como o de Collis(1994), até os textos mais recentes de Teece(2014a, 2014b, 2014c), é possível perceber que CD estão relacionadas com as características que fazem a organização se 
sobressair em um ambiente competitivo, complexo e de alta concorrência tecnológica, ou seja, argumentam que inovação é uma característica das empresas que possuem capacidade dinâmica. Assim, a CD é, em si, a capacidade em inovar mais rapidamente, ou de forma melhor, do que a concorrência (COLLIS, 1994).

Neste sentido, é importante entender que o processo de inovação é desenvolvido a partir de inúmeras variáveis. Talvez ainda haja muito o que estudar para compreender todo o fenômeno da inovação, porém, em muitos casos, ela se deu a partir de processos de aprendizagem. Para Zollo eWinter(2002)defined as routinized activities directed to the development and adaptation of operating routines. It addresses the role of ( 1 , a CD se baseia nos processos de aprendizagem, tanto naqueles que geram novos conhecimentos, os quais se descobre por meio da tentativa de fazer, como aqueles pré-determinados mediante processos de produção e articulação coletiva.Ambos buscam resultados superiores contínuos, o que, na visão dos autores, é produção do conhecimento e fundamenta o surgimento de CD nas organizações. Esse processo, para Collis(1994) é, em si, um tipo de capacidade, a capacidade de aprender a aprender.

Dentre os autores que entendem as capacidades dinâmicas como composta de um conjunto de capacidades a serem desenvolvidas e gerenciadas de forma particular, temos Wang e Ahmed (2007)and has injected new vigour into empirical research in the last decade. Nonetheless, several issues surrounding its conceptualization remain ambivalent. In light of empirical advancement, this paper aims to clarify the concept of dynamic capabilities, and then identify three component factors which reflect the common features of dynamic capabilities across firms and which may be adopted and further developed into a measurement con- struct in future research. Further, a research model is developed encompassing antecedents and consequences of dynamic capabilities in an integrated framework. Suggestions for future research and managerial implications are also discussed.", "author" : [ "dropping-particle" : ", "family" : "Wang", "given" : "Catherine L.", "non-dropping-particle" : "”, "parse-names" : false, "suffix" : "” \}, \{ "dropping-particle” : "”, "family" : "Ahmed", "given" : "Pervaiz K.", "non-dropping-particle" : "”, "parse-names" : false, "suffix" : “” \} ], "container-title" : "International Journal of Management Reviews", "id" : "ITEM-1", "issue" : "1", "issued" : \{ "date-parts" : [ [ "2007"] ] \}, "page" : "31-51", "title" : "Dynamic capabilities: A review and research agenda", "type" : "article-journal", "volume" : "9" \}, "uris" : [ "http://www.mendeley.com/documents/?uuid=049bac0ea161-477a-94cb-e24304be4c76" ] \} ], "mendeley" : \{ "formattedCitation" : "(WANG; AHMED, 2007, que entendem que $A$ capacidade absortiva,se refere à capacidade de uma empresa para reconhecer o valor de novo, informações externas, assimilá-la e aplicá-la. É a capacidade de avaliar e utilizar conhecimentos externos (Cohen e Levinthal,1990).

Sobre capacidade absortiva podemos acrescentar que essa capacidade da organização em identificar, avaliar e concentrar conhecimentos externos é o ponto fundamental para a inovação. Esse processo, aliado à atividade interna de formulação de estratégias e planejamento, pode criar o ambiente ideal para a produção de novas tecnologias. Sobre a capacidade de inovação, o conhecimento externo é um componente crítico. A capacidade de avaliar e utilizar conhecimentos externos são pré-requisitos ao desenvolvimento de novos resultados, e é composto de conhecimento de todos os níveis, do elementar aos conhecimentos científicos ou tecnológicos. (COHEN; GEORGE, 2002; LEVINTHAL, 1989; ZAHRA).

A capacidade absortiva é relacionada à atividade de pesquisa de desenvolvimento como seu antecedente. Logo, esse processo, suas atividades e o conhecimento gerado e compartilhado são variáveis prévias para a capacidade absortiva da organização (COHEN;FOSFURI; TRIBÓ, 2008;GREIS; FISCHER, 2001; LEVINTHAL, 1990c; SCHMIDT, 2005; STOCK; VEUGELERS, 1997)"type" : "article-journal", "volume" : "35" \}, "uris" : [ "http://www.mendeley.com/documents/?uuid=0a640f22-0228-4f3d-9cfc-248f5519b149"] \}, \{ "id" : “ITEM-2", "itemData” : \{ “DOI” : “10.1016/j.omega.2006.06.012", “ISBN" : “03050483”, “ISSN" : “03050483”, "abstract" : "This paper builds upon the theoretical framework developed by Zahra and George [Absorptive capacity: a review, reconceptualization, and extension. Academy of Management Review 2002;27:185-203] to empirically explore the antecedents of potential absorptive capacity (PAC.

Discussão da questão três: No caso, vemos que o pesquisador participou ativamente do desenvolvimento da tecnologia e sua validação in locu, e que constantemente buscou informações sobre o desempenho dos animais, tanto antes quanto depois da implementação das inovações. 
O Zé tomou algumas decisões e influenciou pessoas durante o projeto de desenvolvimento e implantação do programa de melhoramento genético. Isto pode ser levantado e discutida no seguinte sentido: e se o Zé tomasse decisões ao contrário do que está sendo apresentado no Caso, o resultado da pesquisa do Dr. Alexandre, seria o mesmo?

Outro exercício interessante é tentar imaginar com os discentes qual era a realidade da vida do Zé a parir do caso e a partir do poema de Patativa do Assaré. Com os elementos do discurso, com as instituições envolvidas, com um pouco do histórico da produção que o caso apresenta, é possível fazer uma discussão sobre essa realidade e, a partir dela, pensar na relação dessa realidade com o desenvolvimento da inovação.

Base teórica: Alguns pressupostos são necessários para que a capacidade absortiva se manifeste. Os antecedentes podem ser entendidos como "as circunstâncias que devem estar presentes e serem combinadas para que a capacidade se origine" (ESPINOSA; PELÁEZ; GIMÉNEZ, 2007).

Os antecedentes foram identificados por Cohen e Levinthal(1990a): conhecimento prévio já presente na firma, suas competências básicas, métodos de solução de problemas, experiência prévia em aprendizagem, comunicação compartilhada. Além disso,para um grupo de antecedentes, denominou mecanismos de organização interna que orienta processos internos para compartilhar conhecimento para aplicação (exploitation) para fins comerciais.

Uma importante contribuição para a compreensão dos antecedentes de ACAP foi feito por Zahra e George (2002). Os autores resumem em três grandes grupos os antecedentes. Primeiramente, são as fontes externas de conhecimento.Um relevante conhecimento prévio que a empresa possui pode vir de aquisições de outras empresas, convênios e contratos de cooperação, consórcios de P\&D, join ventures e outros exemplos. Em segundo lugar, citam a experiência que é adquirida como a interação da empresa com ambientes onde ela já possui sucesso, com a divulgação de avanços e competências em habilidades que Ihe são particulares, o histórico da empresa em levantar conhecimento em locais já visitados, a prospecção de ambientes, a interação com clientes, o benchmarking, as alianças com outras empresas eo aprendizado que adquiriu a partir do aprender fazendo, o que cria novas rotinas que também influenciam os locais em que a empresa busca conhecimento.

Discussão da questão quatro: No caso, não vemos relatos sobre rotinas de capacidade absortiva, e não se pode concluir que elas não existam como rotinas, procedimentos, atividades pré-determinadas para fundamentar o projeto de pesquisa/inovação.Porém essa questão pode fomentar a discussão sobre rotinas prévias que podem ser implementadas no processo de gestão de inovação.

Base teórica: Diante da não acumulação de capacidade absortiva, a empresa tende a acreditar que o ambiente não muda. Ela deixa de perceber os sinais, não explorar novas informações e, o mais agravante, ela inicia o processo de investimento em áreas e no desenvolvimento de produtos que não estão de acordo com os sinais externos. Automaticamente, isso leva a prejuízos e reduz o nível de inovação, pois suas soluções não são adotadas.

Quando se fala de empresas de Pesquisa, Desenvolvimento \& Inovação, a capacidade absortiva, como foi exposto acima, está relacionada com a capacidade de inovação. Nessas empresas, tradicionalmente, as atividades de P\&D geram conhecimento, porém as atividades de explorar conhecimentos externos são secundárias, e isso pode ser mudado, pois, se ela também tem como uma de suas funções buscar, interagir, discutir sobre novos conhecimentos, isso contribui para a capacidade de absorção da empresa. Para Zahra e George (2002), essa relação deve ser definida por meio de modelos de gestão da capacidade de absorção, tornando-se algo contínuo e positivo para a organização.

Além dessas relações entre ACAP e inovação, estudos recentes identificaram a influência da ACAP no desenvolvimento de novos produtos (NPD) (STOCK; GREIS; FISCHER, 2001).Além disso, outras investigações que, para processos de NPD a ACAP, estão presentes quando manifestada na relação entre as equipes. Percebeu-se que a interação, o compartilhamento de informações prévias e de informações do ambiente externo colabora com a maior efetividade no desenvolvimento de tecnologias (BACKMANN; HOEGL; CORDERY, 2015; DARAWONG, 2015; JANSEN; VAN DEN BOSCH; VOLBERDA, 2005).assimilate, transform, and exploit it - for innovation purposes. Because innovations are usually developed by project teams, this suggests that absorptive capacity, as a construct, may also be usefully applied at the team level. 
Consequently, this study developed a measure for team-level absorptive capacity, investigated the potential influencing factors, and examined its relationship to team effectiveness in terms of product innovativeness in an interorganizational context. Specifically, building on the theory of homophily and information and decisionmaking theories, three factors (social-category similarity, work-style similarity, and knowledge complementarity between the recipient and the partner organization teams

Discussão questão cinco: tomando o caso e revelando o desfecho, é possível ter um panorama completo da pesquisa, desenvolvimento e adoção da inovação.Assim, a partir do cenário completo, é possível discutir sobre as dimensões da ACAP. Essa questão deve ser debatida. Cada dimensão e seus conceitos servirão de filtro para selecionar as informações e perceber a influência da ACAP no desenvolvimento da tecnologia.

Na questão do cruzamento, com a possibilidade de venda ao atravessador relatada pelo Zé e a decisão de não vender por causa da confiança que Zé tem no projeto e na pessoa do pesquisador, é possível perceber que o Dr. Alexandre já havia adquirido, assimilado, transformado e aplicado informações do ambiente. $O$ próprio Zé repara na melhora significativa do desempenho do rebanho (tamanho,cor da pelagem, peso, etc.). Assim, a partir das dimensões, é possível identificar, em intensidade diferentes, cada uma delas, selecionando no texto as falas e a descrição dos desdobramentos na geração da tecnologia dentro do caso.

Base teórica: considerando o conceito de capacidade absortiva, posto acima, é possível falar de suas dimensões (ACAP), que é a capacidade de uma organização aprender a partir da aquisição, assimilação, transformação e exploitation (aplicação do conhecimento externo)(ZAHRA; GEORGE, 2002). Esses autores acrescentam que "estas quatro capacidades representam quatro dimensões da ACAP e desempenham diferentes papéis, porém complementares para explicar como a ACAP nos outcomes da organização". Antes desses autores, Cohen e Levinthal (1990a) dividiram em três essas dimensões que exigem diferentes processos para acontecer nas organizações.As dimensões são: 1) aprendizado exploratório,que é utilizado para reconhecer e entender um novo conhecimento externo.Diferente da estratégia, que foca no conhecimento prévio interno, esses processos dão valor ao conhecimento externo; 2) aprendizagem transformadora, que são as rotinas que combinam novos conhecimentos com o conhecimento existente na empresas. Além disso, com os processos que compartilham e transferem este conhecimento por toda a empresa e 3) Aplicação (exploitation) de como a empresa aplica esses conhecimentos na sua dinâmica(LANE; KOKA; PATHAK, 2006).

No fim das discussões, o professor poderá apresentar o seguinte desfecho do caso: Após cinco anos de levantamento de informações e orientações zootécnicas e veterinárias baseadas no programa de melhoramento genético animal e no sistema de gerenciamento genético de rebanho da Embrapa Caprinos e Ovinos, o Ministério de Abastecimento, Pecuária e Agricultura reconheceu a raça Morada Nova como nova raça de Ovinos. Esse reconhecimento foi devido ao fato de que a raça apresentou peculiaridades relacionadas ao fenótipo, alto desempenho na produção de carne e elevado nível de adaptabilidade às condições do semiárido cearense.

A renovação dos rebanhos, a qualidade e os níveis elevados de produção trouxeram desenvolvimento rural para toda a região e muitos produtores voltaram a trabalhar com a cultura e tirar da propriedade seu sustento e seu negócio. O pesquisador, em 2014, recebeu um prêmio nacional dado a cientistas da área de melhoramento genético animal e, na mesma data, recebeu uma homenagem no município e a chave da cidade de Morada Nova.

\section{Possível organização da aula para uso do caso}

Antes da aula, os alunos podem ser desafiados a escrever sobre quais as dificuldades que o desenvolvimento de inovações enfrenta,seja em um projeto de pesquisa, seja na elaboração de um novo produto. Nesse mesmo sentido, eles devem listar quais informações e as fontes fundamentais para a definição de escopo de uma inovação/projeto/produto.

Durante a aula: os alunos serão organizados em pequenos grupos ou em formato de "U" para leitura individual, ou em grupo, durante quinze minutos. Após a leitura, eles deverão identificar os desafios e variáveis elencadas no exercício e aplicar no caso. Assim, deverão refletir sobre os desafios que correspondem a 
relação inovação x projeto x produto. Por fim, devem entrar em consenso, definindo e priorizando uma lista de variáveis prévias que, na opinião deles,serão fundamentais para o sucesso do desenvolvimento da inovação/projeto/produto (essa atividade levará aproximadamente de vinte a vinte e cinco minutos).

Após o exercício: em outra aula será explanado sobre os conceitos e teorias sobre capacidade absortiva por meio da nota de ensino e, com esse conteúdo, o caso seria novamente visitado e a lista de variáveis seria analisada para comparar aquilo que foi posto pelos alunos e aquilo que a literatura preconiza. Finalmente, os alunos poderiam responder o questionário em grupo e debater as respostas.

\section{Sugestões de bibliografia}

BELCHIOR, E.\& SHIOTSUKI, L. Técnicas de transferência de tecnologias utilizadas em um projeto de melhoramento genético de base comunitária, Coleção de Sistematização de Experiência em Métodos de Transferência de Tecnologia, Intercâmbio e Construção do Conhecimento, Brasília, DF: Embrapa, 2016. (NO PRELO.)

BACKMANN, J.; HOEGL, M.; CORDERY, J. L. Soaking It Up: Absorptive Capacity in Interorganizational New Product Development Teams. Journal of Product Innovation Management, [S.I], v. 32, n. 6, p. 861877, 2015.

BRASIL. Lei no 13.243, de 11 de Janeiro de 2016, que Dispõe sobre estímulos ao desenvolvimento científico, à pesquisa, à capacitação científica e tecnológica e à inovação. . 2016, p. 1-15. Disponível em: <http://www.planalto.gov.br/ccivil_03/_ato2015-2018/2016/lei//13243.htm>. Acesso em: 30 abr. 2016.

CASSOL, A.; CINTRA, R. F. Capacidade absortiva como propulsora da inovação em empresas incubadas de Santa. Revista Ciências Administrativas (RCA), Fortaleza, v. 23, n. 1, p. 9-41, jan./abr. 2017.

CHAUVET, V. Absortive Capacity: Scale Development and Implications for Future Research. Management international, HEC Montréal, v. 19, n.1, p. 113 -129, 2014.

COHEN, W. M.; LEVINTHAL, D. A. Innovation and Learning: the Two Faces of R\&D.The Economic Journal, [S.I], v. 99, n. 397, p. 569-596, Sep.1989.

COHEN, W. M.; LEVINTHAL, D. A. Absorptive Capacity: anew perspective on learning and innovation. Administrative Science Quarterly, [S.I], v. 35, n. 1, p. 128-152, 1990a.

COHEN, W. M.; LEVINTHAL, D. A. Absorptive Capacity: a new perspective on learning and innovation. Administrative Science Quarterly, [S.I], v. 35, n. 1, Special Issue: technology, organizations, and innovation. p. 128-152, Mar. 1990b.

COHEN, W. M.; LEVINTHAL, D. A. Absorptive capacity : a new perspective on learning and innovation. Administrative Science Quarterly [S.I], v. 35, n. 1, p. 128-152, 1990c.

COLLIS, D. J. Research Note: How Valuable Are Organizational Capabilities? Strategic Management Journal, [S.I], v. 15, n. S1, p. 143-152, winter 1994.

DARAWONG, C. The impact of cross-functional communication on absorptive capacity of NPD teams at high technology firms in Thailand. The Journal of High Technology Management Research, [S.I], v. 26, n. 1, p. 38-44, 2015.

EMPRESA BRASILEIRA DE PESQUISA AGROPECUÁRIA (EMBRAPA). Visão 2014-2034: o futuro do desenvolvimento tecnológico da agricultura brasileira. 1a. ed. Brasília, DF: Embrapa Informação Tecnológica, 2014.

ESPINOSA, H. J.; PELÁEZ, J. C.; GIMÉNEZ, A. O. Los antecedentes de lacapacidad de absorción :análisis crítico y proposición de un modelo de integración. International Conference on Industrial Engineering \& Industrial Management, [S.I], n. 2002, p. 559-579, 2007. 
FLATTEN, T. C. et al. A measure of absorptive capacity: Scale development and validation. European Management Journal, [S.I], v. 29, n. 2, p. 98-116, Apr. 2011.

FOSFURI, A.; TRIBÓ, J. A. Exploring the antecedents of potential absorptive capacity and its impact on innovation performance. Omega, [S.I], v. 36, n. 2, p. 173-187, Apr. 2008.

JANSEN, J. J. P.; VAN DEN BOSCH, F. A J.; VOLBERDA, H. W. Managing potential and realized absorptive capacity: How do organizational antecedents matter? Academy of Management Journal, NY, v. 48, n. 6 , p. 999-1015, 2005.

LANE, P. J.; KOKA, B. R.; PATHAK, S. The reification of Absorptive Capacity: a critical review and rejuvenation of the construct. The Academy of Management Review, [S.I], v. 31, n. 4, p. 833-863, Oct. 2006.

LIMA, S. M. V. et al. Inovação e gestão tecnológica em organizações de P\&D: um modelo integrador. Cadernos de Ciência \& Tecnologia, Brasília, v. 21, n. 1, p. 83-103, jan./abr. 2004.

MAGALHÃES, K. A. et al. Panorama e perspectiva mundial da ovinocultura e caprinocultura., 2016 Disponível em: <https://www.embrapa.br/busca-de-noticias/-/noticia/8698648/estudo-aponta-tendenciaspara-caprinocultura-e-ovinocultura-nos-cenarios-nacional-e-internacional>. Acesso em: 30 abr. 2016.

ORGANIZAÇÃO PARA COOPERAÇÃO E DESENVOLVIMENTO ECONÔMICO -OECD AND EUROSTAT. Manual de Oslo: diretrizes para a coleta e interpretação de dados sobre inovação tecnológica. $3^{\text {a }}$. ed. Madrid: Trasga, 2007.

PAEZ, M. L. D. A. Análise e gestão de sistemas de inovação em organizações públicas de P\&D no agronegócio. Brasília/DF: Embrapa Comunicação para Transferência de Tecnologia, 2000.

SCHMIDT, T. What Determines Absorptive Capacity? In:DRUID TENTH ANNIVERSARY SUMMER CONFERENCE, 10., Copenhagen, Denmark. Anais...Copenhagen, Denmark. 2005. p. 1-37.

STOCK, G. N.; GREIS, N. P.; FISCHER, W. A. Absorptive capacity and new product development. The Journal of High Technology Management Research, [S,I], v. 12, n. 1, p. 77-91, Apr. 2001.

TEECE, D. J. Foreword. In: ENGEL, J. S. (Ed.). Global clusters of innovation entrepreneurial engines of economic growth around the world. Berkeley/CA: University of California, v. 57, 2014a. $432 p$.

TEECE, D. J. A dynamic capabilities-based entrepreneurial theory of the multinational enterprise. Journal of International Business Studies, [S.I], v. 45, n. 1, p. 8-37, jan. 2014b.

TEECE, D. J.; PISANO, G.; SHUEN, A. Dynamic capabilities and strategic management. Strategic Management Journal, [S.I], v. 18, n. 7, p. 509-533, Aug.1997.

TODOROVA, G.; DURISIN, B. Absorptive capacity: Valuing a reconceptualization. Academy of Management Review, [S.I], v. 32, n. 3, p. 774-786, Jul. 2007.

VEUGELERS, R. Internal R\{\&\}D expenditures and external technology sourcing. Research Policy, v. 26, n. 3, p. 303-315, Oct. 1997.

WANG, C. L.; AHMED, P. K. Dynamic capabilities: a review and research agenda. International Journal of Management Reviews, [S.I], v. 9, n. 1, p. 31-51, Marc. 2007.

ZAHRA, S. A.; GEORGE, G. Absorptive capacity: A review, reconceptualization, and extension. Academy of Management Review, NY, v. 27, n. 2, p. 185-203, Apr. 2002.

ZOLLO, M.; WINTER, S. G. Deliberate learning and the evolution of dynamic capabilities. Organization Science, v. 13, n. 3, p. 339-351, Jun. 2002. 


\section{ANEXO A}

\section{Panorama e perspectiva nacional da Ovinocultura e Caprinocultura (MAGALHÃES et al., 2016)}

O rebanho nacional de caprinos em 2014 alcançou 8.851.879 cabeças, sendo 8.109.672 cabeças na Região Nordeste (91,6\%), enquanto o rebanho ovino registrou em 2014 o número de 17.614.454 cabeças no País, das quais 10.126 .799 estão no Nordeste (57,5\%) e 5.166.225 na Região Sul (29,3\%). Em termos de tendência nota-se uma diminuição do rebanho na série de 2005 a 2014, para o rebanho caprino, diferentemente do que observa-se para o ovino. A primeira observação é que o rebanho caprino do Brasil é basicamente o efetivo do Nordeste somado a pequenas participações de outros estados. Analisando os últimos dez anos, percebe-se que o rebanho reduziu em aproximadamente $14 \%$. Entretanto, a partir de 2012 o rebanho caprino vem mostrando uma recuperação de 2,4\% no efetivo (Figura 1).

A Figura 2 apresenta o comportamento do rebanho ovino que, apesar de ter também sofrido redução entre 2011 e 2012 (semelhante aos caprinos), apresenta uma tendência de crescimento do efetivo nos últimos dez anos. Talvez a menor concentração regional dos animais, e a crescente demanda por produtos da ovinocultura nos últimos anos, sejam algumas das razões que dão suporte ao crescimento do rebanho no país.

No longo prazo o aumento na produção e consumo dos produtos dessas cadeias é algo que deve ocorrer em função de alguns fatores, seja pelo crescimento natural da população e da renda, seja pela organização desses setores que consiga expandir seu mercado, dado o seu potencial.

Dessa forma, como em outras cadeias, essas questões não serão resolvidas por força de lei, e sim pela percepção de que a organização do setor permite maiores ganhos, atraindo investidores. Por outro lado, o pequeno produtor, inclusive familiar, deve ser colocado como elemento essencial no direcionamento estratégico, dado sua importância produtiva e social. Isso também está relacionado com um aspecto dicotômico dessas cadeias, dado que os principais mercados desses produtos têm duas frentes bem definidas, de um lado o consumo de caráter regional e tradicional, associados a produtos menos elaborados e de baixo valor agregado, de outro, o consumo gourmet, em centros urbanos com maior poder de compra.

Em uma análise de curto prazo, entretanto, as perspectivas não seguem uma tendência tão linear, pois está associada a fatores conjunturais mais imediatos, em que pesam principalmente questões como cenário econômico de curto e médio prazo e condições climáticas. Sob esse foco, ressalte-se o alto grau de incerteza ao considerar tais variáveis, sejam elas climáticas, econômicas ou políticas, as quais conferem um grau de risco que é inerente à atividade agropecuária, no entanto, agravado por um momento especialmente instável e imprevisível no aspecto político, afetando diretamente a economia e os setores produtivos.

Pelo lado da oferta, a instabilidade e a incerteza econômica reduz o incentivo para investimentos, entretanto, a desvalorização da moeda brasileira torna o produto nacional mais competitivo no mercado externo, permitindo que o produtor obtenha uma melhor remuneração ao comercializar em moeda mais valorizada, o que pode induzir uma maior oferta. Ao mesmo tempo, a valorização cambial também faz a importação de insumos e produtos ficar mais onerosa, o que é visto no relatório de perspectivas da Organização para a Cooperação e Desenvolvimento Econômico (OECD) que aponta, entretanto, outros fatores favoráveis para a oferta, como o grande mercado doméstico brasileiro, a evolução sistemática em genética, sanidade e nutrição, combinando em custos mais baixos de produção.Pelo lado da demanda, segundo projeções da OECD, estima-se um aumento do consumo de carne ovina em todo o mundo. Entretanto, as projeções para o consumo de carne ovina no Brasil mostram, se não uma estagnação, uma pequena queda para os próximos anos, o que parece condizente com o cenário de atividade econômica mais retraída e incertezas no País.

A ocorrência do fenômeno climático EI Niño, já em curso, determina condições climáticas potencialmente desfavoráveis para as principais regiões produtoras, em especial na Região Nordeste. (...) Seus efeitos são mais perceptíveis e crônicos na Região Nordeste, dado que essa já contabiliza o quarto ano consecutivo de seca. É óbvio que o efeito de um ano adicional de seca deverá agravar ainda mais as condições produtivas.

(...) No entanto, para a região Nordeste existe influência significativa, afetando todas suas atividades agropecuárias. Assim, dada a significância da região para a ovinocultura e caprinocultura no país e, ainda, o seu histórico climático recente, pode-se considerar que as perspectivas, apesar de pouco favoráveis para o próximo ano no Nordeste, poderá ser compensado, em parte, pelas demais regiões do país. Vale destacar que nos últimos três anos, apesar da seca, os rebanhos caprinos e ovinos aumentaram. A resiliência dessas atividades em condições desafiantes aliada à 
capacidade de adaptação dos produtores à uma nova realidade produtiva, são alguns dos fatores capazes de explicar esse aumento no efetivo do rebanho.

(...) Os efeitos econômicos são sentidos de diversas formas, partindo da desaceleração do ritmo da economia e aumento do desemprego que leva à redução do consumo agregado, como já pode ser percebido com as taxas negativas de crescimento do PIB. O aumento dos preços controlados, como energia e combustíveis, afeta o custo de produção, inclusive de outros insumos, enquanto o aumento da taxa básica de juros onera o custo do capital para o custeio da produção e reduz o investimento.

Submetido em: $16 / 12 / 17$

Aprovado em: 14/03/18 